\title{
The Moderating Effect of Privacy in the Relationships between Residential Livability and Residents' Life Satisfaction
}

\author{
"Sunusi Bashari', Ahmad Hariza Hashim², Asnarulkhadi Abu Samah² and \\ Nobaya Ahmad²
}

First submission: 31 January 2020; Accepted: 17 July 2020; Published: 30 July 2021

To cite this article: Sunusi Bashari, Ahmad Hariza Hashim, Asnarulkhadi Abu Samah and Nobaya Ahmad (2021). The moderating effect of privacy in the relationships between residential livability and residents' life satisfaction. Journal of Construction in Developing Countries, 26(1): 45-62. https://doi.org/10.21315/jcdc2021.26.1.3.

To link to this article: https://doi.org/10.21315/jcdc2021.26.1.3

\begin{abstract}
This article seeks to determine whether privacy has a moderating effect on the relationship between residential livability and life satisfaction among low-income groups in Dutse, Jigawa State, Nigeria. The study utilised a quantitative research design, whereby descriptive and inferential analyses were employed. This was achieved through a wellstructured questionnaire administered to low-cost housing residents in the state. The data were subjected to descriptive analysis using the Statistical Package for Social Science (SPSS) software and structural equation modelling (SEM) using Analysis of Moment Structures (AMOS). The results indicated that about $73.4 \%$ of the residents experienced a low level of life satisfaction. The findings from the SEM showed that the moderating effect of privacy in the relationship between the dwelling unit and life satisfaction was good. Meanwhile, privacy was not a moderator in the relationship between social environment and life satisfaction. Finally, the article revealed that the residents' life satisfaction could be improved if dwelling unit features and privacy were considered in the low-cost housing design. Practically, the study serves as a blueprint for government policy in designing low-cost housing in the future.
\end{abstract}

Keywords: Residential livability, Low-income group, Low-cost housing, Life satisfaction, Privacy

\section{INTRODUCTION}

The overall level of life satisfaction of people in Nigeria-a developing countryranges from a mean of 3.1 to 4.5, which is quite low compared to South Africa, whose mean is 5.43 (Botha, 2013), or a developed country such as Australia, whose life satisfaction mean score ranges between 7.5 and 8.5 (Deaton, 2008). Studies have shown that there is a significant relationship between low levels of life satisfaction and unrest among the population, which could result in loss of life, property (Mafini, 2017) and premature death (Farha, 2019). According to Lynch and Kull (2013), a quality housing environment is among the most important factors affecting the life satisfaction of people, their productivity and standard of living. Similarly, Gou et al. (2018) argued that, socially, the most important factors in overall life satisfaction are constituted in housing. In this regard, the life satisfaction of people deserves special attention of both the government and researchers. This study focuses on residential livability (housing conditions) and its influence on residents' life satisfaction by examining the moderating effect of privacy in the relationship between residential livability and life satisfaction.

\footnotetext{
'Department of Geography, Jigawa State College of Education, Gumel, NIGERIA ${ }^{2}$ Faculty of Human Ecology, Universiti Putra Malaysia, Serdang, Selangor, MALAYSIA *Corresponding author: sunusibashari6@gmail.com
} 
Nicholas and Patrick (2015) defined housing as one of the most important factors used to measure a country's development. It is regarded as a basic human need, providing not only shelter but also the private and dynamic settings for social activities and interactions (Dankani, 2013). As a basic necessity, its importance approximates that of food and clothing (Festus and Amos, 2015). Further, in addressing the importance of housing to human life, Alaghbari et al. (2011) argued that it plays a role in both the social and economic aspects of the world's total living environment.

Unfortunately, despite the importance of housing, most low-income earners in Nigeria live in substandard, poor-quality housing because access to quality housing is far beyond their economic reach (Makinde, 2014). This situation has led to a high rate of housing shortages, both in terms of quality and quantity, in rural and urban centres (Makinde, 2014; Olotuah, 2016). Further, most towns and cities in Nigeria face multiple challenges, such as privacy and poor quality of life, thereby attracting the attention of housing managers and planners towards livability measures (Baig, Rana and Talpur, 2019).

The main focus of livability in relation to the residents of a particular environment is how well this environment serves its inhabitants in the provision of basic services for their living (lyanda et al., 2018). Thus, livability is a relative term, whose meaning depends on the place, the purpose of the assessment, time and the value system of the assessor (lyanda et al., 2018). As a result, scholarly views on livability have varied because of differences in location and planning. For Bandarabad and Shahcheraghi (2012), livability means a good quality of life, while for Okulicz-Kozaryn (2013), it has to do with the well-being of residents in a town, city or region. Livability, therefore, encompasses different views relating to quality of life in any human living environment. It is concerned with optimising the performance and integrity of human life (Ellis and Roberts, 2016).

In the previous literature, the concept of livability is seen as culturally specific. For Kennedy, Buys and Miller (2015), culture is important in determining the housing form and design and this importance cannot be overemphasised (Olayiwola, Adeleye and Jiboye, 2006). Rapoport (2014) found a strong relationship between culture and environmental design and as such, cultural differences must be considered in the design procedure.

The concept of culture is broad and includes factors such as values, norms, social interaction and privacy (Pandey, Garg and Bharat, 2013). Privacy is emphasised here because it plays a major role in influencing people's lives and well-being, especially through housing (Ahmad Hariza and Zaiton, 2010). Privacy usually acts as a regulating mechanism in housing and can be achieved through behavioural and environmental mechanisms. Behavioural mechanisms are influenced by socio-cultural factors (Altman, 1977). Bahammam (1987) and Mortada (2011) emphasised that privacy in a traditional Islamic housing unit is necessary and consists of four main layers: privacy between neighbours' dwellings, privacy between males and females, privacy between family members inside the house and individual privacy. However, previous studies have not paid sufficient attention to the effect of privacy as a cultural aspect in moderating the relationship between residential livability and life satisfaction, especially among residents of public low-cost housing in Dutse, Jigawa State, Nigeria.

In Jigawa State, Muslims comprise the predominant population in public low-cost housing and have traditionally valued family privacy in the home, as required by Islam (Umar, 2018). Therefore, people in Jigawa State have a 
preference for housing designs that make provisions for a private space for women and separated from men public spaces, especially when it comes to ceremonies and other activities. In this study, privacy is presented as an important aspect of culture, especially in terms of building design and is used as a moderator in the relationship between residential livability and residents' life satisfaction. In addition, as housing privacy is more relevant to attributes of dwelling unit features and social environment factors (bedroom, toilet, bathroom, kitchen and social interaction), this study will only focus on the moderating effect of privacy in the relationship between three factors: dwelling unit, the social environment as residential livability dimensions and life satisfaction among low-cost housing residents in Jigawa State.

\section{Objectives}

The aim of the article is to understand the role of privacy in the relationship between residential livability and life satisfaction through the following objectives:

1. To explore the level of life satisfaction among residents of low-cost housing in Jigawa State, Nigeria.

2. To examine the moderating effect of privacy in the relationship between residential livability and life satisfaction.

\section{LITERATURE REVIEW}

According to Furlan (2016), in order to make a place comfortable, residents must be provided with appropriate areas or spaces to meet, eat, sit and drink. If housing units do not offer the features expected by residents, such conditions will generate parental stress and reduce normal family activities, thereby affecting children's socio-emotional functioning (Lynch and Kull, 2013).

Livability is a general concept related to the quality of life, healthy communities and sustainability (Ghasemi, Hamzenejad and Meshkini, 2019). The main focus of livability in relation to the people of a particular environment is how well that environment services its residents with basic needs for their living (lyanda et al., 2018).

In residential livability, neighbourhood facilities have a positive impact on people's perception of life because of the many impacts on residents, which lead to their life satisfaction and dictate their subjective well-being (Bayulken and Huisingh, 2015). According to Ismail et al. (2015), residential environments become livable if residents are provided with basic needs such as health facilities, a recreational centre and open green areas, all of which will eventually lead to improvements in life satisfaction. To increase the livability of a residential environment, authentic amenities should be provided, with the intention of supporting social and commercial activities of relevance to the life satisfaction of the residents of a particular environment (Chun-Hao and Tsai, 2013).

Bayulken and Huisingh (2015) emphasised that there is a strong relationship between a neighbourhood's physical attributes-such as open spaces, natural environment accessibility of public facilities and recreational facilities-and social dimensions-such as its socio-economic status, the pattern of social networks, cultural factors and perceptions of housing livability. A study by Hamsa et al. (2010) 
on the perceptions of residents of the Melati residential area, Malaysia, on air quality, noise, street lighting and traffic congestion revealed that residents preferred a silent environment, less traffic congestion and high security control. To these people, this is what they considered to be a livable environment. In newly constructed public low-cost housing in Kuala Lumpur, Malaysia, the residents wanted more space for bedrooms, toilets and a living area to improve their housing conditions. They also wanted improvements to the safety of the estates, security control and less noise in the neighbourhood (Mohit, Ibrahim and Rashid, 2010). Meanwhile, Cuñado and Gracia (2013) confirmed residents' desire for good air quality and a healthy environment as attributes of a livable environment.

Furthermore, Ukoha and Beamish (1997) stated that public housing inhabitants in Abuja, Nigeria, identified neighbourhood facilities such as schools, hospitals, markets and distance to the place of work as the most important facilities for them. Also, according to Ibem and Amole (2012), occupants of public core housing in Abeokuta, Ogun State, Nigeria, indicated a desire for access to basic services, social infrastructure and a greater number of bedrooms in their housing units. In Lagos, Nigeria, Ebiaride and Umeh (2015) revealed that residents of public low-cost housing estates had a preference for shopping malls, schools, recreational centres and hospitals near to their housing estates. Meanwhile, the majority of residents in Niger, Nigeria, preferred four or more bedrooms, a safe environment and security services (Mohit and lyanda, 2017).

To ensure an improvement in the life satisfaction of residents, the government should create an enabling environment through the provision of infrastructure and services that are difficult for people to provide for themselves, for example, water supply, electricity, a good road network and public transport (Rigon, 2018). In addition, the availability of and nearness to schools affect the life satisfaction of the residents in a given residential area (Mafini, 2017). In the study of Meyer and Dunga (2014), housing conditions were found to be significant for life satisfaction. Life satisfaction is an umbrella that encompasses social issues, design problems, environmental life as well as socio-demographic and psychological characteristics (Türkoğlu et al., 2019). It is a global measure of subjective well-being and can be measured using the Satisfaction with Life Scale (Diener et al., 1985). Diener and Ryan (2015) concluded that a high level of life satisfaction greatly improves people's lives in four major areas: social relations, work and income, health and longevity and societal benefits. Life satisfaction is largely identified as a central aspect of human welfare. Dodge et al. (2012) consider it to be linked to happiness and Diener and Ryan (2015) believe that well-being consists wholly or largely in being satisfied with one's life. Thus, empirical research on well-being depends heavily on life satisfaction studies (Haybron, 2007). The other important element affecting life satisfaction is privacy.

Privacy is an important factor in residential livability and is controlled by building design (Kennedy, Buys and Miller, 2015). Privacy is defined as a regulator of access, which includes freedom from being bothered and some have considered it to include situations characterised by quietness and peacefulness within the boundaries of the home (Ahmad Hariza and Zaiton, 2010). The concept of privacy, including the various grades of privacy, is culturally specific; therefore, Western conceptions of privacy vary from their Eastern counterparts (Zaiton, 2007). According to the Western view, privacy has more to do with the personal and personal space, while the Eastern world emphasises the privacy of the family or 
collective over and above the personal or individual (Ahmad Hariza, Harlina and Asnarulkhadi, 2009).

The issue of privacy in a traditional Muslim house depends on the country context; for instance, in Middle Eastern countries such as the Arab-Gulf countries, Iran, Turkey and Saudi Arabia, weight is placed on privacy through the separation of male and female spaces. This requirement affects the layout and design of homes (Othman, Aird and Buys, 2015). Conversely, Malaysia places emphasis on modesty and hospitality (Razali and Talib, 2013).

Most studies on livability have focused on residents' perceptions of residential livability dimensions without directly or indirectly relating them to the residents' life satisfaction (Baig, Rana and Talpur, 2019; Lukuman et al., 2017; Mohit and lyanda, 2015). Also, few studies have discussed the effects of privacy on the relationship between residential livability and life satisfaction (Zaiton, 2007). Thus, this study focuses on the effects of privacy on the relationship between residential livability and life satisfaction among residents of public low-cost housing in Jigawa State, Nigeria.

\section{METHODOLOGY}

\section{Research Design and Approach of the Study}

This research was based on a survey design that utilised a questionnaire for the data collection. The survey method was used because it is commonly deployed to obtain primary data related to the beliefs, behaviours, attitudes or background of a large number of people by means of the questionnaire (Neuman, 2006). The study focused on how residents perceived residential livability in the context of their life satisfaction, making this design relevant to the study. Thus, information was obtained from the respondents without altering their situation.

\section{Population size of the study}

The population of this study comprised eligible low-cost housing occupants of Jigawa State, amounting to a total of 3,156 households (JSHA [Jigawa State Housing Authority], 2014). According to the JSHA (2014), there were seven low-cost housing locations in the state: the Olayinka housing estate (128 units), the Takur housing estate (540 units), the Yadi housing estate (520 units), the Red-bricks housing estate (88 units), 744 housing estate (744 units), the Fatara housing estate (636 units) and the Dan Masara housing estate (500 units).

\section{Sample size}

The sample size was calculated using the Krejcie and Morgan (1970) formula based on the population size $(3,156)$. The following formula was used to arrive at the sample size (S) for this research:

$$
S=\frac{X^{2} N P(1-P)}{d^{2}(N--1)+X^{2} P(1-P)}
$$


where,

$S$ = Required sample size,

$N=$ The total population of the study,

$P=$ The proportion of the population, which, based on the table construct, was assumed to be at 0.05 because this value magnitude yielded the maximum possible sample size required,

$d=$ The degree of accuracy expressed as a proportion of 0.05 and

$x^{2}=$ The table value of the chi-square for 1 degree of freedom at the desired confidence level.

$$
S=\frac{3.84 * 3,156 * 0.05(1-0.05)}{0.05^{2}(3,156--1)+3.84 * 0.05(1-0.05)}
$$

Therefore, $S=341$.

However, as Singh and Masuku (2013) suggested, it is a good idea to add $10 \%$ of the sample size of the respondents to avoid drop-out. As such, 375 respondents were selected for the study. Between the months of June and July 2019, 400 questionnaires were distributed of which a total of 372 questionnaires were duly completed.

\section{Sampling Procedure}

According to Hakin (1984), multi-stage sampling is most appropriate when the sample selection involves two or three stages. Gravetter and Forzano (2016) also stated that, in large sample surveys, the multi-stage cluster sampling technique is most suitable for collecting samples from the cluster. In this study, a combination of these sampling types was employed as a sampling procedure in three stages.

\section{Stage 1: Selection of housing estate}

There were seven existing low-cost housing estates in Jigawa State, all of which were purposely selected; from which the sample was drawn. They were selected in order to have a larger sample size, which is ideal for more reliable results (Cohen, 1988).

\section{Stage 2: Selection of number of participants in each housing estate}

This was aimed at finding the sample size of each low-cost housing estate. In this stage, the number of participants was found through the formula developed by Cohen (1988):

$$
n i=\frac{N i}{N} n
$$


where,

$n$ = Total sample size selected from the table,

$N=$ Total population of the households in all housing units,

$\mathrm{ni}=$ Sample size in each housing estate and

$\mathrm{Ni}=$ Total population of the households in the selected housing estates .

For example, the Olayinka housing estate comprised 128 housing units, $N=3,156$ (total number of all selected housing units in all selected housing estates): $n i=$ sample size, $\mathrm{Ni}=128$ and $n=341$, as described.

$$
\text { Sample size }=\frac{128}{3,156} \times 341=14
$$

Therefore, 14 participants were required from the Olayinka housing estate and after incorporating the additional 10\% suggested by Singh and Masuku (2013), the final sample size amounted to 15 participants.

\section{Stage 3: Selection of each participant from the housing units}

This involved the selection of the 375 participants across all the selected lowcost housing estates, depending on the sample size of each low-cost housing estate. This was achieved through a systematic sampling technique, which was undertaken through several steps. First, the sampling interval was determined from each low-cost housing estate by dividing the total number of housing units (population) by the sample size of the different low-cost housing estates. For instance, the Olayinka housing estate $=128 / 15=9$ (interval). Second, for the first housing unit, this was obtained from a table of random numbers, where one of the authors closed their eyes, used a pen and pointed to a number falling within the population of that particular low-cost housing estate, which depended on the choice of the author in terms of the digits appearing in the rows and columns. Third, the subsequent housing units were selected by adding the sampling interval (e.g., 9). The same procedure was followed across all the low-cost housing estates. The total population of all housing units $(3,156)$, the total sample size $(341)$ and the total number of households in each housing estate were used to arrive at the following number of respondents in each housing estate: Olayinka (15), Takur (64), Yadi (62), Red-bricks (11), 744 housing (88), Fatara (76) and Dan Masara (59), amounting to a total of 375 respondents. Following the addition of $10 \%$ more participants, 400 questionnaires were distributed and 372 questionnaires were retrieved from the distributed questionnaires. The data were analysed descriptively using the Statistical Package for Social Science (SPSS) version 20 software (IBM Corp., New York, USA).

\section{Measurement of Residents' Level of Life Satisfaction and the Moderating Effect of Privacy in the Relationship between Residential Livability and Life Satisfaction}

The questionnaire was administered by the researcher and seven enumerators. The data were analysed with the IBM SPSS version 20 software for descriptive analyses and the Analysis of Moment Structures (AMOS) version 22 (IBM Corp., New York, USA) software for the structural equation modelling (SEM). Descriptive analyses were conducted to determine the current status of life satisfaction among the low-cost 
housing estate residents. This was achieved through the application of a standard scale (Satisfaction with Life Scale) (Diener et al., 1985). To examine the moderating effect of privacy in the relationship between the residential livability dimensions (exogenous variables - IV) and life satisfaction (endogenous variales - DV), SEM was conducted after data checking and preparation, such as confirmatory factor analysis (CFA) and the measurement model. The structural model represents the interrelationship between the IV and DV variables and was done by assessing the model validity and hypothetical paths (Hair et al., 2010). At this stage, the study examined the interactive effects between life satisfaction (LS) as the DV and dwelling unit features (DUF), social environment (SE), physical environment (PE), security and crime (SC) and functional environment (FE) as the IV. However, the model had to fit the analysis, which was confirmed through the test of overall model fitness (the fit indices and recommended values are as shown in Tables 1 and 2).

Table 1. Fit Indices and Recommended Values for CFA

\begin{tabular}{lc}
\hline Fit Indices & Recommended Values \\
\hline Relative chi-square (CMIN/D) & $\leq 5.0$ \\
Comparative fit index (CFI) & $\geq 0.90$ \\
Incremental fit index (IFI) & $\geq 0.90$ \\
Normed fit index (NFI) & $\geq 0.90$ \\
Tucker-Lewis index (TLI) & $\geq 0.90$ \\
Factor loading & Between 0.5 and 1.0 \\
\hline
\end{tabular}

The test for the overall model fitness, as depicted in Table 2 and Figure 1, showed that all the factor loadings were above 0.50 and that the absolute fit indices (relative chi-square [3.800] and root mean square error of approximation [RMSEA] [0.061]) as well as the incremental fit indices (goodness of fit index [GFI] [0.905], CFI [0.909], IFI [0.909]) met the recommended values. Because of the model fit, no further improvements to the model were conducted (Rencher and Christensen, 2012). Thus, the model was assumed to be valid.

As stated in the previous figure, a structural model was used to examine the moderating effect of housing privacy on the relationship between residential livability dimensions (dwelling unit and social environment) and life satisfaction. The dwelling unit features and social environment factors were more closely related to housing privacy in terms of attributes (bedroom, toilets, social interaction, etc.) than physical environment or functional factors (play area, parking space, etc.), which is why these two dimensions were selected. The following hypotheses were proposed:

$\mathrm{H}_{1}$ : Housing privacy moderates the relationship between dwelling units and the life satisfaction of the respondents.

$\mathrm{H}_{2}$ : Housing privacy moderates the relationship between the social environment and life satisfaction of the respondents. 
Table 2. Dimensions and Attributes of Residential Livability Meeting the Recommended Values after CFA

\begin{tabular}{|c|c|c|}
\hline$S / N$ & $\begin{array}{l}\text { Dimensions of Residential } \\
\text { Livability }\end{array}$ & $\begin{array}{l}\text { Attributes of Each Dimension of } \\
\text { Residential Livability }\end{array}$ \\
\hline \multirow[t]{5}{*}{1} & Dwelling units & DU3: Number of bedrooms \\
\hline & & DU6: Number of toilets \\
\hline & & DU1: Size of the housing unit \\
\hline & & DU5: Ventilation spaces \\
\hline & & DU7: Number of bathrooms \\
\hline \multirow[t]{3}{*}{2} & Social environment & SE5: Trust your neighbour \\
\hline & & SE3: Neighbours' friendliness \\
\hline & & SE4: Neighbourhood helpful \\
\hline \multirow[t]{5}{*}{3} & Physical environment & PE3: Masjid (mosque)/church \\
\hline & & PEl 4: Market \\
\hline & & PE1 1: Motor park/bus stop \\
\hline & & PE6: Workplace \\
\hline & & PE7: Police station \\
\hline \multirow[t]{5}{*}{4} & Safety and crime & SC4: Safety from accident \\
\hline & & SC5: Property safety \\
\hline & & SC3: Safety from crime \\
\hline & & SC1: Police protection \\
\hline & & SC2: Vigilante protection at night \\
\hline \multirow[t]{9}{*}{5} & Functional environment & FE16: Access to electricity/power supply \\
\hline & & FE15: Access to water supply \\
\hline & & FE9: Distance to mosque/church \\
\hline & & FE3: Distance to school \\
\hline & & FE4: Distance to hospital \\
\hline & & FE2: Distance to workplace \\
\hline & & FE12: Availability of public transport \\
\hline & & FEl: Distance to town centre \\
\hline & & FE6: Distance to market \\
\hline
\end{tabular}

Testing the moderating effect in AMOS involved two steps:

1. Testing the moderating effect on the overall model and testing the presence of moderation.

2. Testing the moderating effect on the hypothesised path (Hair et al., 2010). 


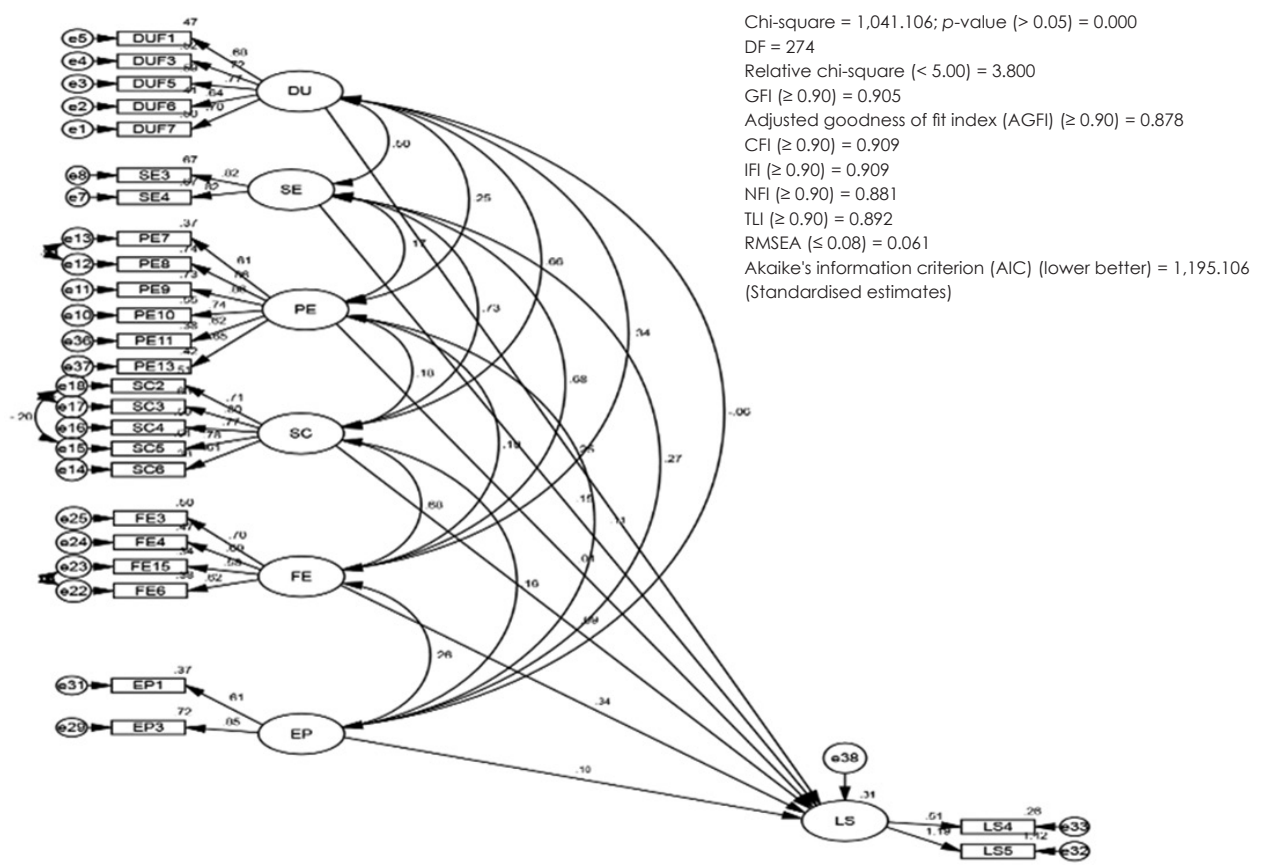

Figure 1. Revised Structural Model

Testing the moderating effect of housing privacy against the overall model involved comparing the unconstrained (variant-group) model against the measurement residual (invariant-group) model. Moderation was established if the unconstrained (variant-group) model was better than the measurement residual (invariant-group) model. The unconstrained model assumed that the models for low and high privacy were different, while the measurement model assumed that the models for low and high privacy were identical. In order to test the model comparison, the unconstrained model should be better than the measurement residual model. To achieve this, the chi-square value $\left(x^{2}\right)$ for the unconstrained model should be lower than that of the measurement residual model at $p<\alpha$. Table 3 presents the output of the moderating effect of housing privacy on the overall model (i.e. to test the presence of the moderation effect).

Table 3. Testing the Presence of Moderation Effects of Housing Privacy on the Overall Model

\begin{tabular}{lcc}
\hline Models & CMIN $\left(\mathbf{x}^{2}\right)$ & $\boldsymbol{p}$-Value \\
\hline Unconstrained model & $1,291.473$ & 0.000 \\
Measurement residual model & $1,512.788$ & 0.000 \\
\hline
\end{tabular}

The results showed that both models were significant at $a<0.05$. In addition, the value of the unconstrained model $(1,291.473)$ was less than that of the measurement residual model $(1,512.788)$. Since the models were both significant, the next step 
was to test the significance of the $x^{2}$ difference. The output of the $x^{2}$ difference revealed that the difference between the unconstrained and constrained models was significant, $\left.\Delta x^{2}=1512.788 ;-1291.473\right)$; $d f=77(625 ;-548), p=0.000$, thereby revealing the presence of a moderation effect of housing privacy. After confirming the presence of moderation, the next step was to test the moderation effect on the individual hypothesised path, as specified in $\mathrm{H}_{1}$ and $\mathrm{H}_{2}$.

To test the moderation effect on the hypothesised path, two decision criteria were proposed to examine whether a path was moderated by a moderator:

1. To verify whether beta $(\beta)$ for group 1 was significant and $\beta$ for group 2 was non-significant or that both groups were significant, with one being positive and the other being negative (Hair et al., 2010).

2. The check for the significance of the critical ratio (CR) for difference. A significant $C R(C R>1.96)$ implies a moderated path, while a nonsignificant $C R(C R<1.96)$ implies that the path is not moderated.

\section{RESULTS AND DISCUSSIONS}

\section{Life Satisfaction of the Residents}

Table 4 presents the summary of the analysis describing the respondents' level of life satisfaction in relation to residential livability. The results revealed that, out of the 372 respondents, $273(73.4 \%)$ exhibited a low level of life satisfaction as residents of lowcost housing estates in Jigawa State. About 79 (21.2\%) showed a moderate level of life satisfaction, while only 20 (5.4\%) experienced a high level of life satisfaction. This result was achieved through categorisation, which was derived from the results obtained using the standard Satisfaction with Life Scale, as described earlier (as shown in Table 4).

To categorise the variable, the maximum and minimum Likert scale scores were determined (maximum $=7 ;$ minimum $=1$ ). Subsequently, the differences between the minimum and maximum scores were used to determine the range (Likert scale score $=7-1=6$ ), which was then used to calculate the class interval (calculated by taking the range and dividing it by the number of categories [low, moderate and high]).

Class interval $=6 / 3=2$. Finally, the value of the class interval was used to categorise the variables into low, moderate and high. Table 4 presents the summary and interpretation of the levels of life satisfaction and housing privacy.

Table 4. Level of Life Satisfaction of Residents

\begin{tabular}{lcccccc}
\hline Level & Frequency & $\%$ & Mean & $\begin{array}{c}\text { Standard } \\
\text { Deviation } \\
\text { (SD) }\end{array}$ & Min. & Max. \\
\hline Low life satisfaction (1.00 to 2.99) & 273 & 73.4 & 3.54 & 0.84 & 1 & 7 \\
Moderate life satisfaction (3.00 to 4.99) & 79 & 21.2 & & & & \\
High life satisfaction (5.00 to 7.00) & 20 & 5.4 & & & & \\
\hline
\end{tabular}


Table 4 presents a summary of the analysis describing the respondents' level of life satisfaction in terms of residential livability. The results were achieved through categorisation, which was derived from results obtained using the standard Satisfaction with Life Scale, as described earlier (as shown in Table 4).

Based on the results, a majority of the residents expressed a low level of life satisfaction because of factors such as a lack of facilities and amenities in the respective housing estates. This was similar to findings by Muhammad et al. (2015), who revealed that a low level of life satisfaction among residents was related to low housing estate standards and that, in most cases, the housing design did not address the socio-cultural lifestyle of the low-income groups in Abuja, Nigeria. A majority of low-income groups live under poor housing conditions characterised by a lack of basic amenities and facilities and overcrowding, exacerbating their quality of life (Ugonabo and Emoh, 2013). This is similar to the findings of Deaton (2008) and Botha (2013), who pointed out that in developing countries, such as Nigeria, people's overall level of life satisfaction ranges between means of 3.1 and 4.5, a figure which is quite low compared to South Africa-with mean above 5.43or developed countries such as Australia-with life satisfaction scores ranging from 7.5 to 8.5. The result is also consistent with the finding of Umar (2018), who revealed that the life satisfaction of residents of the Fatara housing estate in Jigawa State was low due to insufficient facilities and amenities. Moreover, inadequate infrastructure and the substandard quality of the dwelling units led to low life satisfaction in terms of the health and general welfare of the residents (Abah et al., 2015). Low life satisfaction among the low-cost housing residents of Jigawa State is similar to that of the residents in the housing estates in Minna, Niger State, Nigeria, which were in need of neighbourhood facilities to improve life satisfaction or make their life easier (Ayoola et al., 2017). Generally, residents' life satisfaction can be improved through a mix of better infrastructure, proper policies, human capital development and environmental concerns (Kondapi et al., 2019).

\section{Moderation Effect of Housing Privacy on the Relationship between Residential Livability and Life Satisfaction}

The moderation analysis for this study, as presented in Table 5, was based on the criteria of Hair et al. (2010). The moderating variable (housing privacy) was categorised into two groups (low housing privacy [LHP] and high housing privacy $[H H P])$. The mean value was used for the categorisation, where mean values between ( $M=1.00$ to 2.50) were categorised as low and mean values between $(M=2.51$ to 4.00$)$ were categorised as high housing privacy.

The result revealed that housing privacy moderated the relationship between the dwelling unit and life satisfaction (LHP $[\beta=0.726, p=0.350]$; HHP $[\beta=-0.310, p=0.149])$. Thus, $H_{1}$ was supported. However, there was no moderating effect of housing privacy on the relationship between social environments and life satisfaction (LHP $[\beta=-0.034, p=0.957]$; $\operatorname{HHP}[\beta=-0.144$, $\mathrm{p}=0.307])$. Thus, $\mathrm{H}_{2}$ was not supported.

In summary, the structural output results indicated that privacy in housing moderated the relationship between the dwelling unit and life satisfaction of the residents of low-cost housing in Jigawa State. Thus, hypothesis $\mathrm{H}_{1}$ was supported. Privacy is culturally specific and culture has great influence on the built environment, for instance, in relation to changes in the physical structure of the residential area. This was supported by Ghasemi, Hamzenejad and Meshkini (2019), who noted that 
the arrival of Islam in Iran brought some changes in cultural, social and ideological constructions, which affected the physical or spatial structure of Iranian cities through Islamic ideologies. Likewise, Emirati people in Dubai wanted the design of their housing units to reflect their culture in terms of the organisation of the interior and the use of construction materials (Bande et al., 2019). The finding is similar to that of Kennedy, Buys and Miller (2015), who revealed that about $91 \%$ of the residents of multi-story apartment dwellings in Brisbane, Australia, valued privacy. About $60 \%$ of the residents considered privacy as "important" or "very important", while about $31 \%$ considered privacy as "extremely important". However, the residents were generally fairly satisfied with privacy from neighbours, with a mean of 3.67 , which was found to affect their life satisfaction. Based on these results, privacy can be regarded as a variable that moderates the relationship between dwelling units and life satisfaction. However, the social environment was not found to be moderated by housing privacy and as explained previously, $\mathrm{H}_{2}$ was rejected.

Table 5. Moderation Effect on the Relationship between Dimensions of Residential Livability and Life Satisfaction

\begin{tabular}{lcc}
\hline Hypothesis Path & $\begin{array}{c}\text { Standardised Regression Weight } \\
\text { Beta }(\boldsymbol{\beta})\end{array}$ & $\mathrm{p}$-Value \\
\hline Dwelling Unit & 0.726 & \\
LHP & -0.310 & 0.350 \\
HHP & & 0.149 \\
Social Environment & -0.034 & \\
LHP & -0.144 & 0.957 \\
HHP & & 0.307 \\
\hline
\end{tabular}

\section{CONCLUSION}

A majority of the residents of low-cost housing estates in Jigawa State (about 73.4\%) exhibited a low level of life satisfaction. This low life satisfaction resulted from several issues, including poor housing design and insufficient services and facilities in most low-cost housing estates. The findings from the SEM revealed that privacy in the relationship between the dwelling unit and life satisfaction was a good moderator. However, privacy was not a moderator in the relation between social environment and life satisfaction. The dimension of dwelling unit features was found to be the most important compared to other residential livability dimensions (e.g., social environment, physical environment, safety and crime and functional) in terms of its role in predicting the residents' life satisfaction. The findings support the assumption of Western theories of privacy, which view privacy as non-universal in nature but, rather, as influenced by the values of the individual or society. Therefore, privacy might be influenced by individual norms and values or by those of a society or collective, as indicated by the low-cost housing residents in Jigawa State. Nigeria's national housing policy emphasises that every Nigerians are entitled to decent and livable housing. Therefore, this study will serve as a guide to policymakers in terms of increasing the flexibility of housing policies and focusing more on socio-cultural 
aspects for beneficiaries. The research concludes that the life satisfaction of lowcost housing estate residents in Jigawa State, Nigeria, can be improved if housing units are livable and privacy is addressed.

Finally, the study recommends several solutions to overcoming the problems of low-cost housing in Nigeria: the government should create a means of getting financial support from mortgage banks/World Bank to embark on the production of large low-cost housing; the government should involve beneficiaries and other stakeholders in the housing design and construction of low-cost housing estates; and the government should ensure the provision of basic facilities and infrastructure before the allocation of houses to beneficiaries. Although the study is limited to low-cost housing and was restricted to Jigawa State, the authors suggest further research on similar issues, with an emphasis on comparisons of the key concepts of livability, life satisfaction and privacy among different income groups belonging to different geographical areas.

\section{ACKNOWLEDGEMENTS}

This research is an aspect of a doctorate (PhD) thesis which was conducted in Jigawa State, Nigeria. This article was written with contributions of Professor Ahmad Hariza Hashim, Professor Asanarul-Khadi Abu Samah and Associate Professor Nabaya Ahmad. These people deserved to be mentioned considering their effort to ensure this research have reached this stage.

\section{REFERENCES}

Abah, A.R.S., Walker, S.D.J., Ogunleye, A.A.F.O. and Hirst, L. (2015). Well-Being and Citizenship in Urban Nigeria. London: ICF International.

Ahmad Hariza, H. and Zaiton A.R. (2010). Privacy and housing modifications among Malay urban dwellers in Selangor. Pertanika Journal of Social Science and Humanities, 18(2): 259-269.

Ahmad Hariza, H., Harlina, M.A. and Asnarulkhadi, A.S. (2009). Urban Malays' userbehaviour and prespective on privacy and spatial organization of housing. International Journal of Archtectural Research, 3(1): 197-208. http://doi.org/ 10.26687/archnet-ijar.v3i1.263.

Alaghbari, W.E., Salim, A., Dola, K. and Ali, A.A.A. (2011). Developing affordable housing design for low income in Sana'a, Yemen. International Journal of Housing Markets and Analysis, 4(1): 84-98. https://doi.org/10.1108/ 17538271111111857.

Altman, I. (1977). Privacy regulation: Culturally universal or culturally specific? Journal of Social Issues, 33: 66-84.

Ayoola, A.B., Kemiki, O.A., Adeniran, A.A. and Abdulkareem, S. (2017). Assessment of households' satisfaction with neighbourhood facilities in selected residential locations of Minna Urban. Available at: https://www.researchgate.net/ publication/315651445.

Bahammam, A.S. (1987). Architectural patterns of privacy in Saudi Arabian housing. MArch diss. McGill University. 
Baig, F., Rana, I.A. and Talpur, M.A.H. (2019). Determining factors influencing residents' satisfaction regarding urban livability in Pakistan. International Journal of Community Well-Being, 2: 91-110. https://doi.org/10.1007/s42413019-00026-w.

Bandarabad, A. and Shahcheraghi, A. (2012). Livable street in urban environment: An adaptive design approach. Advances in Environmental Biology, 6(3): 1063-1067.

Bande, L., Young, K., Adan, R., Khoukhi, M., Aldarmaki, A.A.R.A., Aldhaheri, A.S.S. and Alneyadi, A.S.A. (2019). Housing programmes in UAE: Case study analysis based on regional sustainable standards and local microclimate. Journal of Physics: Conference Series, 1343: 012027. https://doi.org/10.1088/17426596/1343/1/012027.

Bayulken, B. and Huisingh, D. (2015). Perceived "quality of life" in eco-developments and in conventional residential settings an explorative study. Journal of Cleaner Production, 98: 253-262. https://doi.org/10.1016/j.jclepro.2014.10.096.

Botha, F. (2013). Life satisfaction and education in South Africa: Investigating the role of attainment and the likelihood of education as a positional good. Social Indicators Research, 118: 555-578. https://doi.org/10.1007/s11205 -013-0452-2.

Chun-Hao, L. and Tsai, M.-C. (2013). Is the easy life always the happiest? Examining the association of convenience and well-being in Taiwan. Social Indicators Research, 117(3): 673-688. https://doi.org/10.1007/s11205-013-0392-x.

Cohen, J. (1988). Statistical Power Analysis for the Behavioural Sciences. 2nd Ed. Mahwah, NJ: Lawrence Erlbaum Associates.

Cuñado, J. and Gracia, F.P.D. (2013). Environment and happiness: New evidence for Spain. Social Indicators Research, 1 13(3): 549-567. https://doi.org/10.1007/ s1 1205-012-0038-4.

Dankani, I. (2013). Affordable housing provision in Kano North Western Nigeria: The imperative for the creation of sustainable city. International Journal of Management and Social Sciences Research, 2(8): 189-198.

Deaton, A. (2008). Income, health and well-being around the world: Evidence from the Gallup World Poll. Journal of Economic Perspectives, 22(2): 53-72.

Diener, E. and Ryan, K. (2015). Subjective well-being: A general overview. South African Journal of Psychology, 39(4): 391-406.

Diener, E., Emmons, R.A., Larsen, R.J. and Griffin, S. (1985). The Satisfaction with Life Scale. Journal of Personality Assessment, 49(1): 71-75.

Dodge, R., Daly, A., Huyton, J. and Sanders, L. (2012). The challenge of defining wellbeing. International Journal of Wellbeing, 2(3): 222-235. https://doi.org/ 10.5502/ijw.v2i3.4.

Ebiaride, E.C. and Umeh, O.L. (2015). Factors influencing users' satisfaction in public and private estate in Lagos, Nigeria. ATBU Journal of Environmental Technology, 8(2): 30-41.

Ellis, P. and Roberts, M. (2016). Leveraging Urbanization in South Asia: Managing Spatial Transformation for Prosperity and Livability. Washington, DC: South Asia Development Matters, World Bank Group.

Farha, L. (2019). Adequate Housing as a Component of the Right to an Adequate Standard of Living. Geneva: OHCHR (Office of the United Nations High Commissioner for Human Rights) and UN-Habitat (United Nations Human Settlement Programme). 
Festus, I.A. and Amos, I.O. (2015). Housing policy in Nigeria: An overview. American International Journal of Contemporary Research, 5(2): 53-59.

Furlan, R. (2016). Urban design and social livability the revitalization of the Corniche in Doha. American Journal of Environmental Engineering, 6(3): 73-87. https://doi.org/10.5923/j.ajee.20160603.01.

Ghasemi, K., Hamzenejad, M. and Meshkini, A. (2019). The livability of Iranian and Islamic cities considering the nature of traditional land uses in the city and the rules of their settlement. Habitat International, 90: 102006. https://doi.org/10.1016/j.habitatint.2019.102006.

Gou, Z., Xie, X., Lu, Y. and Khoshbakht, M. (2018). Quality of Life (QoL) survey in Hong Kong: Understanding the importance of housing environment and needs of residents from different housing sectors. Internalional Journal of Environmental Research and Public Health, 15(2): 219. https://doi.org/10 $.3390 /$ ijerph 15020219 .

Gravetter, F.J. and Forzano, L.-A.B. (2016). Research Methods for Behavioral Sciences. 5th Ed. Stamford, CT: Cengage Learning.

Hair, J.F., Black, W.C., Babin, B.J. and Anderson, R.E. (2010). Multivariate Data Analysis. 7th Ed. Upper Saddle River, NJ: Prentice Hall.

Hakin, D.G. (1984). Multistage sampling designs in fisheries research: Applications in small streams. Canadian Journal of Fisheries and Aquatic Sciences, 41(11): 1575-1591.

Hamsa, A., Masao, M., Shuhei, I. and Yosuke, N. (2010). Perception analysis of living environment at Taman Melati residential area. Journal of Asian Architecture and Building Engineering, 5(2): 377-384.

Haybron, D. (2007). Life satisfaction, ethical reflection and the science of happiness. Journal of Happiness Studies, 8: 99-138.

Ibem, E.O. and Amole, D. (2012). Residential satisfaction in public core housing in Abeokuta, Ogun State, Nigeria. Social Indicators Research, 113(1): 563-581. https://doi.org/10.1007/s11205-012-0111-z.

Ismail, F., Jabar, I.L., Janipha, N.A.I. and Razali, R. (2015). Measuring the quality of life in low cost residential environment. Procedia - Social and Behavioral Sciences, 168: 270-279. https://doi.org/10.1016/j.sbspro.2014.10.232.

lyanda, S.A., Ismail, O., Fabunmi, F.O., Adeogun, A.S. and Mohit, M.A. (2018). Evaluating neighborhoods livability in Nigeria: A structural equation modelling (SEM) approach. International Journal of Built Environment and Sustainability, 5(1): 47-55. https://doi.org/10.11113/ijbes.v5.n1.245

JSHA (Jigawa State Housing Authority) (2014). Jigawa State Housing Authority Annual Report, 2014. Dutse, Nigeria: JSHA.

Kennedy, R., Buys, L. and Miller, E. (2015). Residents' experiences of privacy and comfort in multi-storey apartment dwellings in subtropical Brisbane. Sustainability, 7(6): 7741-7761. https://doi.org/10.3390/su7067741.

Kondapi, A., Kumar, T., Sait, U., Bhalla, K. and Ashok, S.S. (2019). A case-study of slums: An informal housing for people below poverty line (BPL) in India. Journal of Physics: Conference Series, 1343: 012152. https://doi.org/10.1088/1742 $-6596 / 1343 / 1 / 012152$

Krejcie, R.V. and Morgan, D.W. (1970). Determining sample size for research activities. Educational and Psychological Measurement, 30: 607-610. 
Lukuman, M., Sipan, I., Raji, F. and Aderemi, O.S. (2017). Sustainable livable housing: A review of what traditional urban areas residents find important. International Journal of Built Environment and Sustainability, 4(3): 190-198. https://doi.org/10.11113/ijbes.v4.n3.212.

Lynch, A.D. and Kull, M. (2013). Relations between housing characteristics and the well-being of low-income children and adolescents. American Psychological Association, 49(9): 1775-1789. https://doi.org/10.1037/a0031033.

Mafini, C. (2017). Economic factors and life satisfaction trends from South African communities. Acta Universitatis Danubius, 13(3): 155-168.

Makinde, O.O. (2014). Housing delivery system, need and demand. Environment, Development and Sustainability, 16(1): 49-69. https://doi.org/10.1007/s10668 -013-9474-9.

Meyer, D.F. and Dunga, S.H. (2014). The determinants of life satisfaction in a lowincome, poor community in South Africa. Mediterranean Journal of Social Sciences, 5(13): 163-171. https://doi.org/10.5901/mjss.2014.v5n13p 163.

Mohit, M.A. and lyanda, S.A. (2017). Low-income housing in Nigeria: A liveability investigation. Asian Journal of Quality of Life, 2(6): 43-51. https://doi.org/ 10.21834/ajqol.v2i6.45.

Mohit, M.A. and lyanda, S.A. (2015). City liveability and housing in Nigeria: A case study of low-income housing in Niger State. Procedia - Social and Behavioral Sciences, 2(1): 1-13.

Mohit, M.A., Ibrahim, M. and Rashid, Y.R. (2010). Assessment of residential satisfaction in newly designed public low-cost housing in Kuala Lumpur, Malaysia. Habitat International, 34(1): 18-27. https://doi.org/10.1016/j.habitatint.2009.04.002.

Mortada, H. (2011). Traditional Islamic Principles of Built Environment. London/New York: RoutledgeCurzon.

Muhammad, Z., Johar, F., Sabri, S. and Jonathan, Z.U. (2015). A review of housing provision and the challenges of sustainable housing delivery in the Federal Capital Territory Abuja, Nigeria. Jurnal Teknologi (Sciences and Engineering), 1 (1): 23-31.

Neuman, W.L. (2006). Social Research Methods: Qualitative and Quantitative Approaches. Upper Saddle River, NJ: Pearson Education.

Nicholas, E.O. and Patrick, D.D. (2015). A review of governmental intervention on sustainable housing provision for urban poor in Nigeria. International Journal of Social Science Studies, 3(6): 40-48. https://doi.org/10.111114/ijsss.v3i6.1069.

Okulicz-Kozaryn, A. (2013). City life: Rankings (livability) versus perceptions (satisfaction). Social Indicators Research, 110(2): 433-451. https://doi.org/10 .1007/s $11205-011-9939-x$.

Olayiwola, L., Adeleye, O. and Jiboye, A. (2006). Effect of socio-cultural factors on housing quality in Osogbo, Nigeria. Paper presented at the CIB W107 Construction in Developing Countries International Symposium "Construction in Developing Economies: New Issues and Challenges". Santiago, Chile, 18-20 January.

Olotuah, A.O. (2016). An appraisal of housing and neighbourhood quality in residential estates in Akure, Nigeria. Mediterranean Journal of Social Sciences, 7(3): 424-431. https://doi.org/10.5901/mjss.2016.v7n3s1p424.

Othman, Z., Aird, R. and Buys, L. (2015). Privacy, modesty, hospitality and the design of Muslim homes: A literature review. Frontiers of Architectural Research, 4(1): 12-23. https://doi.org/10.1016/j.foar.2014.12.001. 
Pandey, R.U., Garg, Y.K. and Bharat, A. (2013). Understanding qualitative conceptions of livability: An Indian perspective. International Journal of Research in Engineering and Technology, 2(12): 374-380. https://doi.org/ 10.15623/ijret.2013.0212064.

Rapoport, A. (2014). On the cultural responsiveness of architecture. Journal of Architectural Education, 41 (1): 10-15. https://doi.org/10.1080/10464883.1987 .10758460 .

Razali, N.H.M. and Talib, A. (2013). Aspects of privacy in Muslim Malay traditional dwelling interiors in Melaka. Procedia - Social and Behavioral Sciences, 105: 644-654. https://doi.org/10.1016/j.sbspro.2013.11.067.

Rencher, A.C. and Christensen, W.F. (2012). Confirmatory Factor Analysis: Methods of Multivariate Analysis. $3 \mathrm{Ed}$. Hoboken, NJ: John Wiley and Sons.

Rigon, A. (2018). An analysis of well-being in urban Nigeria. Development in Practice, 28(2): 195-207. https://doi.org/10.1080/09614524.2018.1421618

Singh, A.S. and Masuku, M.B. (2013). Fundamentals of applied research and sampling techniques. International Journal of Medical and Applied Sciences, 2(4): 124-132.

Türkoğlu, H., Terzi, F., Salihoğlu, T., Bölen, F. and Okumuş, G. (2019). Residential satisfaction in formal and informal neighborhoods: The case of Istanbul, Turkey. International Journal of Architectural Research, 13(1): 112-132. https://doi.org/10.1108/arch-12-2018-0030.

Ugonabo, C.U. and Emoh, F.I. (2013). The major challenges to housing development and delivery in Anambra State of Nigeria. Civil and Environmental Research, 3(4): 1-20.

Ukoha, O.M. and Beamish, J.O. (1997). Assessment of residents' satisfaction with public housing in Abuja, Nigeria. Habitat International, 21 (4): 445-460.

Umar, M.M. (2018). Housing as a motivating factor towards enhancing workers' performance: A case of Jigawa State civil servants in Dutse. MSc diss. Federal University Dutse.

Zaiton, A.R. (2007). Privacy and modification of terrace housing among Malay occupants in Klang, Malaysia. PhD diss. University Putra Malaysia. 